\title{
Optimization and outcomes of patients who decline blood transfusion during complex spine surgery: a retrospective cohort study
}

\author{
Alexandra E. Kisilevsky, MD, PhD • Liam Stobart, MD • \\ Kristine Roland, MD · Alana M. Flexman, MD
}

Received: 23 February 2016/Revised: 25 May 2016/Accepted: 10 June 2016/Published online: 20 June 2016

(C) Canadian Anesthesiologists' Society 2016

\section{To the Editor,}

Allogeneic transfusion and perioperative anemia are associated with increased morbidity and mortality, requiring perioperative blood conservation strategies to minimize exposure to blood products. ${ }^{1}$ Patients who decline blood transfusion may be at risk of severe perioperative anemia despite blood conservation techniques. ${ }^{2}$ As spine surgery can be associated with high blood loss, ${ }^{3}$ the care of patients undergoing complex spine surgery who decline transfusion is challenging, yet little evidence exists to guide management. We sought to compare the perioperative hemoglobin nadir, blood conservation techniques, and outcomes in patients undergoing spine surgery who refuse and accept transfusion.

With approval from the University of British Columbia Research Ethics Board (H14-01007), we identified adult patients who underwent elective spine surgery ( $>$ four hours) between June 1, 2004 and May 9, 2014 in our Blood Utilization Program database. We excluded patients with a spinal tumour, coagulopathy, and/or staged or emergent surgery. Patients who refused transfusion were randomly matched 1:4 to patients who accepted transfusion (controls) based on the year of surgery ( \pm one year), sex, site (cervical $v s$ thoracolumbar spine), referral hemoglobin $( \pm$ $\left.10 \mathrm{~g} \cdot \mathrm{L}^{-1}\right)$, and age $( \pm 10 \mathrm{yr})$. Patient characteristics,

A. E. Kisilevsky, MD, PhD · L. Stobart, MD .

A. M. Flexman, MD (凶)

Department of Anesthesiology, Pharmacology and Therapeutics,

University of British Columbia, Vancouver, BC, Canada

e-mail: alana.flexman@vch.ca

K. Roland, MD

Department of Pathology and Laboratory Medicine, University of British Columbia, Vancouver, BC, Canada anesthetic and procedural information, hemoglobin levels, blood conservation strategies, and 30-day outcomes were extracted from the record. A two-way factorial analysis of variance that accounted for matched sets was used to determine the association between group allocation and continuous outcome variables. A conditional Poisson regression model with grouping on the matched sets was used to determine the association between groups and the number of blood conservation techniques.

Of 1,274 patients undergoing elective major spine surgery, seven patients declined transfusion (all selfidentified as Jehovah's Witnesses). After excluding 179 patients, we matched the refusal patients to 27 controls (one refusal matched to only three controls). Baseline characteristics, thoracolumbar location, surgical duration, and blood loss were similar between the groups.

The average perioperative hemoglobin nadir in the refusal and control groups was similar (Table), as was the lowest hemoglobin level recorded (refusal $61 \mathrm{~g} \cdot \mathrm{L}^{-1} \mathrm{vs}$ control $\left.68 \mathrm{~g} \cdot \mathrm{L}^{-1}\right)$. Five control patients $(18 \%)$ received a red blood cell transfusion. Refusal patients underwent a significantly greater median [interquartile range (IQR)] number of perioperative blood conservation strategies than their matched controls (5 [3-7] vs 3 [0-6], respectively; incident risk ratio, $1.7 ; 95 \% \mathrm{CI}, 1.1$ to $2.5 ; P=0.014$ ) (Table). One refusal patient underwent a "limited decompression." The median [IQR] lengths of hospital stay were similar in the refusal (6 [5-8] days) and control group (7 [6-13] days). No deaths occurred in either group.

Our results are from a matched cohort of patients who declined transfusion and underwent spine surgery with similar hemoglobin nadirs and outcomes compared to patients who accepted transfusion. In contrast to the controls, patients who refused transfusion underwent a greater number of blood conservation strategies, including 
Table Perioperative blood conservation strategies and outcomes of patients who declined or accepted blood product transfusion during complex elective spine surgery

\begin{tabular}{|c|c|c|c|c|}
\hline Parameter & Refusal $(n=7)$ & Control $(n=27)$ & Difference $(95 \%$ CI) & $P$-value* \\
\hline Days in BUP program & $45(28)$ & $111(22)$ & $-66(-157$ to 24$)$ & 0.14 \\
\hline Hemoglobin at referral to BUP & $136(14)$ & $136(13)$ & $0(-11$ to 11$)$ & 0.89 \\
\hline Preoperative hemoglobin & $147(9)$ & $139(11)$ & $8(-2$ to 17$)$ & 0.07 \\
\hline Change in hemoglobin & $11(14)$ & $4(11)$ & $8(-2$ to 17$)$ & 0.09 \\
\hline Ferritin level at referral to BUP & $101(52)$ & $205(55)$ & $-104(-342$ to 134$)$ & 0.30 \\
\hline Preoperative ferritin level & $136(110)$ & $200(319)$ & $-65(-474$ to 345$)$ & 0.62 \\
\hline Change in ferritin level & $50(163)$ & $-2(75)$ & $52(-76$ to 178$)$ & 0.36 \\
\hline Hemoglobin nadir & $102(20)$ & $94(16)$ & $8(-6$ to 22$)$ & 0.26 \\
\hline Blood conservation strategies & 5 [4-6] & $3[2-4]$ & $2(0$ to 4$)$ & 0.014 \\
\hline Oral iron & $6(86)$ & $25(93)$ & & \\
\hline Intravenous iron & $3(43)$ & $4(15)$ & & \\
\hline Erythropoietin & $5(71)$ & $12(44)$ & & \\
\hline PAD & $0(0)$ & $2(7)$ & & \\
\hline $\mathrm{ANH}$ & $3(43)$ & 0 & & \\
\hline Anti-fibrinolytic & $7(100)$ & $17(63)$ & & \\
\hline Cell salvage & $7(100)$ & $19(70)$ & & \\
\hline Permissive hypotension & $3(43)$ & 0 & & \\
\hline
\end{tabular}

Results are expressed as the mean (SD), median [IQR] or the number (\%) unless otherwise stated. All hemoglobin values are reported in $\mathrm{g} \cdot \mathrm{L}^{-1}$. All ferritin values are reported in $\mu \mathrm{g} \cdot \mathrm{L}^{-1}$

Refusal refers to patients who declined blood transfusion. Control refers to patients who accepted blood transfusion

$\mathrm{ANH}=$ acute normovolemic hemodilution; $\mathrm{BUP}=$ blood utilization program; $\mathrm{CI}=$ confidence interval; $\mathrm{IQR}=$ interquartile range; $\mathrm{PAD}=$ preoperative autologous donation; $\mathrm{SD}=$ standard deviation

* $P$-values were derived from factorial analysis of variance (continuous variables) and a conditional Poisson regression model (number of strategies)

modification of the surgical technique in one case. Our results suggest that patients willing to accept transfusion could also benefit from similar, more aggressive blood conservation strategies. These results are similar to those reported for Jehovah's Witness patients undergoing hip arthroplasty ${ }^{4}$ but are in contrast to results in the cardiac surgery literature, where refusal patients had higher preoperative and nadir hemoglobin levels. ${ }^{5}$ Contrasting results may be due to our study limitations, which include the evolution in clinical practice during the study. It was also a single-centre study and had a small sample size.

Overall, patients who refused transfusion underwent successful major spine surgery with aggressive blood conservation strategies. Although the low number of patients in the study limits our ability to draw conclusions, large trials are not feasible in this uncommon population.

Source of funding Dr. Alana Flexman is supported by a Vancouver Acute Department of Anesthesia Research Merit Award.

Conflicts of interest None declared.
Editorial responsibility This submission was handled by Dr. Philip M. Jones, Associate Editor, Canadian Journal of Anesthesia.

\section{References}

1. Shander A. Surgery without blood. Crit Care Med 2003; 31: S70814.

2. Shander A, Javidroozi $M$, Naqvi $S$, et al. An update on mortality and morbidity in patients with very low postoperative hemoglobin levels who decline blood transfusion (CME). Transfusion 2014; 54: 2688-95.

3. Hu SS. Blood loss in adult spinal surgery. Eur Spine J 2004; 13(Suppl 1): S3-5.

4. Harwin SF, Pivec R, Naziri Q, Issa K, Mont MA. Is total hip arthroplasty a successful and safe procedure in Jehovah's Witnesses? Mean five-year results. Hip Int 2014; 24: 69-76.

5. Bhaskar B, Jack RK, Mullany D, Fraser J. Comparison of outcome in Jehovah's Witness patients in cardiac surgery: an Australian experience. Heart Lung Circ 2010; 19: 655-9. 